\title{
Research on adsorption performance of magnetic bio-char for tetracycline in water
}

\author{
Qiankun Hong \\ Zhejiang Tongji Vocational College of Science and Technology, Hangzhou, 311231, China
}

\begin{abstract}
In this paper, waste coconut shells are used as raw materials to prepare the corresponding biochar (BC), and further prepare magnetically modified magnetic bio-char (MBC), and explore the adsorption of $\mathrm{BC}$ and $\mathrm{MBC}$ on the amount of adsorbent, adsorption time and $\mathrm{pH}$. The recyclability of $\mathrm{BC}$ and $\mathrm{MBC}$ were contrasted. The results of the study found that compared to $\mathrm{BC}$, the magnetically modified $\mathrm{MBC}$ has a larger specific surface area and richer functional groups, which provides more adsorption sites for the adsorption and removal of tetracycline. It can be used in different adsorbent dosages and adsorption times. Under the conditions of $\mathrm{pH}$ and $\mathrm{pH}$, it shows better adsorption performance. In addition, $\mathrm{MBC}$ has better recycling properties than $\mathrm{BC}$, which has higher application prospects. This research provides a theoretical basis for the utilization of waste resources and the removal of antibiotics in wastewater.
\end{abstract}

\section{Introduction}

In recent years, with the abuse of antibiotics, a large number of antibiotics have entered the water environment. Tetracycline antibiotics (TCs) are one of the most commonly used antibiotics in human health care and animal feed additives ${ }^{[1]}$. However, only a very small part of antibiotics can be digested and absorbed by the stomach and intestines of humans and animals ${ }^{[2]}$. Most antibiotics are excreted into the body through feces in the form of parent compounds. Because antibiotics are not easily biodegradable, they will remain and accumulate in the environment, causing serious environmental problems Pollution. Residual antibiotics in the environment have aroused everyone's attention because they pose a potential long-term adverse threat to human health and natural ecosystems ${ }^{[3-4]}$. Therefore, how to efficiently and quickly remove residual TCs and other antibiotic pollutants in the environment has become an environmental problem that needs to be solved urgently.

At present, the main methods of treating antibiotic wastewater are: membrane separation, biodegradation, photocatalytic degradation, chemical oxidation, adsorption $^{[5-10]}$. Among them, the adsorption method is recognized as one of the most promising methods due to its high removal efficiency, simple operation and low $\operatorname{cost}^{[11-13]}$. However, for any adsorption method to treat wastewater, its adsorption efficiency depends on the choice of a suitable adsorbent ${ }^{[14]}$. Therefore, the development of high-efficiency and low-cost adsorption materials is the key to promoting its practical application. Bio-char is a kind of porous carbon material formed by high temperature pyrolysis of biomass under anaerobic or anaerobic conditions. It not only has high specific surface area, porosity and abundant functional groups, but also has a wide range of sources and simple preparation process. It has been successfully used in the treatment of wastewater, and creating great possibilities for the resource utilization of waste biomass. Nevertheless, it is difficult to separate the bio-char in the system after adsorption, and there is a risk of secondary pollution.

Therefore, this study intends to combine bio-char and magnetic materials to make a magnetic bio-char composite material, to investigate its adsorption capacity for antibiotics under different conditions, and to provide theoretical basis and technical support for the removal of antibiotics.

\section{Materials and methods}

\subsection{Material}

First, the coconut husk is cleaned, dried and ground in an oven, and then passed through a 100-mesh sieve. Then the coconut shell powder was placed in an alumina porcelain boat and calcined in a tube furnace, heated to $800^{\circ} \mathrm{C}$ at a rate of $5^{\circ} \mathrm{C} / \mathrm{min}$ under the protection of nitrogen, maintained for 5 hours, and cooled to room temperature to obtain black $\mathrm{BC}$ powder.

Slowly add aqueous $\mathrm{FeCl}_{3} \quad(3 \mathrm{~g} / 25 \mathrm{~mL})$ to $\mathrm{FeSO}_{4} \cdot 7 \mathrm{H}_{2} \mathrm{O}(6.15 \mathrm{~g} / 250 \mathrm{~mL})$, and stir thoroughly (200 $\mathrm{rpm})$ at $60-70^{\circ} \mathrm{C}$ for about $5 \mathrm{~min}$. The solution was added to the aqueous ultrasonic dispersion $\mathrm{BC}$ at room temperature and stirred slowly for $30 \mathrm{~min}$. The $\mathrm{pH}$ value of the $\mathrm{Fe}^{2+} / \mathrm{Fe}^{3+} / \mathrm{BC}$ suspension was adjusted to $\sim 10.5$ by adding $10 \mathrm{MNaOH}$ dropwise and stirring by the following method, and then aged at room temperature for 24 hours. Iron oxide nucleates and precipitates on the

\footnotetext{
* Corresponding author: hongqk0918@163.com
} 
surface of biochar during the aging process. The product is filtered (Whatman No. 1 filter paper), rinsed with distilled water, and then the obtained MBC is filtered with ethanol, and then dried overnight in a drying oven at $50^{\circ} \mathrm{C}$ and $1 \mathrm{~atm}$.

\subsection{Material characterization}

The Merlin ultra-high resolution field emission scanning electron microscope of Zeiss, Germany was used for SEM analysis to determine the surface morphology characteristics of biochar. X-ray diffraction (XRD) analysis was performed using the D8 ADVANCEX-ray diffractometer $(\mathrm{Cu}$ target, $\mathrm{K}$ a as radiation source, Lynx Exe array detector, wavelength $0.15418 \mathrm{~nm}$ ) from Bruker, Germany, scanning speed 10 o $\cdot$ min-1, scanning The range is $5 \sim 80^{\circ}$, the working voltage is 40 $\mathrm{kV}$, the current is $40 \mathrm{~mA}$, and the working temperature is room temperature. Use Perkin Elmer's 1725X infrared spectrometer to perform Fourier transform infrared spectroscopy (FT-IR), the scanning range is $4000 \sim 400$ $\mathrm{cm}-1$, the resolution of the instrument is $4 \mathrm{~cm}-1$, the number of scanning is 64 times, and the test temperature is $25{ }^{\circ} \mathrm{C}$, using potassium bromide tablet method for sample preparation. BET analysis uses American Kantar Autosorb iQ to analyze the specific surface area and micropores of the material. The test conditions are: helium is used as the carrier gas, degassed at $80{ }^{\circ} \mathrm{C}$ for $12 \mathrm{~h}$, and the specific surface area of the adsorbent is measured by the N2 adsorption method., The t-plot method measures the surface area and volume of the micropores, and the DFT method calculates the average micropore diameter. For elemental analysis, an elemental analyzer (Vario EL cube, Elementar, Germany) was used to determine the $\mathrm{C}, \mathrm{H}, \mathrm{N}$, and $\mathrm{S}$ content of biochar, and the $\mathrm{O}$ content was obtained by subtraction.

\subsection{Tetracycline determination}

Weigh $1 \mathrm{~g}$ of tetracycline hydrochloride and dissolve it in $1 \mathrm{~L}$ of deionized water to prepare TC stock solution. Dilute an appropriate amount of stock solution into a series of concentration gradient standard solutions. An ultraviolet-visible spectrophotometer was used to measure the absorbance of the standard solution at 355 $\mathrm{nm}$, and a standard curve was drawn from the absorbance and the mass concentration of TC.

\subsection{Batch adsorption experiments}

Weigh $1.0 \mathrm{~g}$ of tetracycline hydrochloride, dry it at $105{ }^{\circ} \mathrm{C}$ for 2 hours, add deionized water to make the volume to $1000 \mathrm{~mL}$, and configure it as a $1000 \mathrm{mg} / \mathrm{L}$ TC standard stock solution. The TC solution used in the experiment was obtained by diluting the abovementioned standard stock solution. At $25{ }^{\circ} \mathrm{C}$, shake with 130rmin-1.

\subsubsection{The effect of adsorbent dosage on adsorption}

Add a certain amount of biomass charcoal and magnetic biomass charcoal to the TC solution, set the dosage of the adsorbent to $0.2-1.2 \mathrm{~g} / \mathrm{L}$, set the temperature at $25^{\circ} \mathrm{C}$, and oscillate for $36 \mathrm{~h}$ to calculate the removal rate and adsorption capacity.

\subsubsection{The effect of adsorption time on adsorption}

Add $0.4 \mathrm{~g} / \mathrm{L}$ of $\mathrm{BC}$ and $\mathrm{MBC}$ to a series of conical flasks containing $50 \mathrm{~mL}$ and $50 \mathrm{mg} / \mathrm{L}$ TC dye solution, respectively, and shake in a constant temperature water bath shaker. Take out the Erlenmeyer flask at different time intervals of $0 \sim 300 \mathrm{~min}$, measure the absorbance of $\mathrm{TC}$ in the supernatant at a wavelength of $355 \mathrm{~nm}$, calculate the dye removal rate, and analyze the effect of adsorption time on the TC adsorption effect;

$$
\begin{aligned}
& \mathrm{q}=(\mathrm{c} 0-\mathrm{c}) \mathrm{V} / \mathrm{m} \\
& \mathrm{\eta}=(\mathrm{c} 0-\mathrm{c}) / \mathrm{c} 0 \times 100 \%
\end{aligned}
$$

$\mathrm{q}$ is the adsorption capacity of $\mathrm{BC}$ and $\mathrm{MBC}, \mathrm{mg} / \mathrm{g}$; $\mathrm{c} 0$ is the concentration of the TC solution before adsorption, $\mathrm{mg} / \mathrm{L}$; $\mathrm{c}$ is the concentration of the remaining $\mathrm{TC}$ solution after adsorption, $\mathrm{mg} / \mathrm{L} ; \mathrm{V}$ is the volume of the $\mathrm{CR}$ solution, $\mathrm{L}$; $\mathrm{m}$ is the quality of $\mathrm{BC}$ and $\mathrm{MBC}$, $\mathrm{g}$.

\subsubsection{The effect of initial $\mathrm{pH}$ on adsorption}

Adjust the $\mathrm{pH}(4 \sim 11)$ of the TC solution with $0.5 \mathrm{~mol} / \mathrm{L}$ $\mathrm{HCl}$ and $1 \mathrm{~mol} / \mathrm{L} \mathrm{NaOH}$ solution, add $0.4 \mathrm{~g} / \mathrm{L}$ adsorbent to the $50 \mathrm{mg} / \mathrm{L} \mathrm{TC}$ dye solution, and shake to balance the adsorption After centrifugation, the supernatant was taken to measure the absorbance of $\mathrm{TC}$, the removal rate was calculated, and the effect of initial $\mathrm{pH}$ on the adsorption was studied.

\subsection{Recyclability experiment}

Add $0.06 \mathrm{~g}$ of $\mathrm{BC}$ and $\mathrm{MBC}$ to $150 \mathrm{~mL}, 100 \mathrm{mg} / \mathrm{L}$ of TC solution respectively. After the adsorption is saturated, place them in a $\mathrm{H}_{2} \mathrm{O}_{2}$ solution with a concentration of $0.003 \mathrm{mmol} / \mathrm{L}$ for desorption for 1 hour. After washing with deionized water several times Centrifuge, and then dry in a constant temperature drying oven at $60^{\circ} \mathrm{C}$ for $6 \mathrm{~h}$. The dried samples were repeated four times in accordance with the above steps for recyclability experiments.

\section{Results and discussion}

\subsection{Effect of adsorbent dosage}

Add different masses of $\mathrm{BC}$ and $\mathrm{MBC}$ to a $100 \mathrm{mg} / \mathrm{L}$ tetracycline solution, and you can see the effect of $\mathrm{BC}$ and MBC dosage on TC adsorption as shown in the figure. It can be found that the unit adsorption amount of $\mathrm{TC}$ decreases with the increase of $\mathrm{BC}$ and MBC dosage. When the dosage increases from $0.1 \mathrm{~g} / \mathrm{L}$ to $1.2 \mathrm{~g} / \mathrm{L}$, the unit adsorption capacity of $\mathrm{BC}$ and $\mathrm{MBC}$ on $\mathrm{TC}$ decreases from $149.8 \mathrm{mg} / \mathrm{g}$ and $201.2 \mathrm{mg} / \mathrm{g}$ to $29.3 \mathrm{mg} / \mathrm{g}$ 
and $76.3 \mathrm{mg} / \mathrm{g}$, respectively. The main reason is that under the condition of constant tetracycline concentration, although with the increase of the adsorbent dosage, its surface area and effective adsorption sites increase, but the increase of dosage will cause the utilization rate of $\mathrm{BC}$ and $\mathrm{MBC}$ to gradually decrease, and the unit adsorption The amount is then reduced. The adsorption effect of $\mathrm{MBC}$ on $\mathrm{TC}$ is much higher than that of $\mathrm{BC}$. This may be because the magnetically modified $\mathrm{MBC}$ has a larger specific surface area and can provide more adsorption sites.

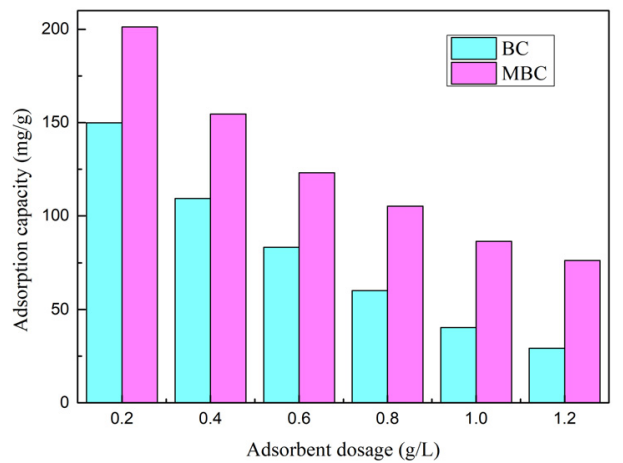

Fig. 1. Effect of adsorbent dosages on TC adsorption of BC and $\mathrm{MBC}$.

\subsection{Effect of contact time}

The adsorption under different contact times and the subsequent time to reach adsorption equilibrium is an important parameter of the adsorption process. The influence of contact time on the adsorption effect of tetracycline is shown in the figure. At the initial stage of adsorption, the adsorption speeds of $\mathrm{BC}$ and $\mathrm{MBC}$ to $\mathrm{TC}$ are both faster This is mainly due to the sufficient active sites on the surface of the initial adsorbent. As time goes by, the adsorbed material gradually fills the active sites of the adsorbent, and adsorption becomes more and more difficult, and the upward trend of adsorption slows down. Finally, BC and $\mathrm{MBC}$ reach adsorption equilibrium at $240 \mathrm{~min}$ and $90 \mathrm{~min}$, respectively. They are $89.9 \mathrm{mg} / \mathrm{g}$ and $155.2 \mathrm{mg} / \mathrm{g}$ respectively. The magnetically modified MBC has a higher specific surface area and can provide more active sites for the adsorption of tetracycline. Therefore, MBC can not only reach the adsorption equilibrium faster, but also the adsorption equilibrium amount is much higher than that of BC.

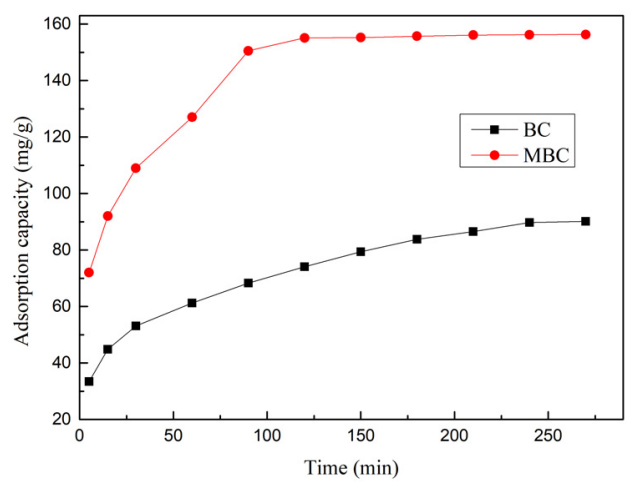

Fig. 2. Effect of contact time on $\mathrm{TC}$ adsorption of $\mathrm{BC}$ and $\mathrm{MBC}$.

\subsection{Effect of pH}

Solution $\mathrm{pH}$ plays a vital role in the adsorption process, because $\mathrm{pH}$ can change the existence of $\mathrm{TC}$ in the aqueous solution and affect the surface charge of the material, which in turn affects the adsorption behavior. Figure 3 shows the effect of $\mathrm{pH}$ on the adsorption capacity of $\mathrm{BC}$ and $\mathrm{MBC}$. The results show that the adsorption capacity of $\mathrm{BC}$ and $\mathrm{MBC}$ both have a great influence. For $\mathrm{BC}$ and $\mathrm{MBC}$, the adsorption capacity showed a gradual decrease as the $\mathrm{pH}$ value increased. When the $\mathrm{pH}$ value was 11.0 , the adsorption capacity of $\mathrm{BC}$ and $\mathrm{MBC}$ were $35.3 \mathrm{mg} / \mathrm{g}$ and $82.1 \mathrm{mg} / \mathrm{g}$, respectively. However, the adsorption capacity of MBC has always been higher than that of $\mathrm{BC}$. This is mainly because the pore structure of $\mathrm{MBC}$ is richer, the aromaticity is enhanced, and the hydrophilicity and polarity are also increased, the surface functional groups are more abundant, and the oxygen-containing functional groups are increased.

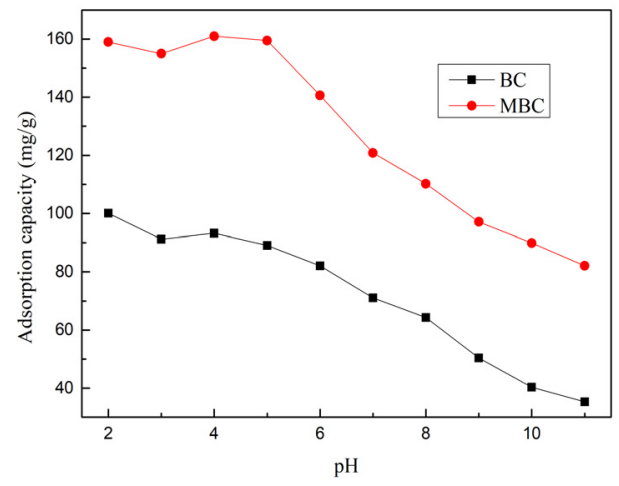

Fig. 3. Effect of $\mathrm{pH}$ on $\mathrm{TC}$ adsorption of $\mathrm{BC}$ and $\mathrm{MBC}$.

\subsection{Recycling}

The reusable performance of the adsorbent is an important indicator for evaluating whether the adsorbent has practical application value. As shown in the figure, the unit adsorption capacity of $\mathrm{MBC}$ and $\mathrm{BC}$ after 5 adsorption and desorption has decreased to varying degrees. This may be Because there are still some 
adsorption sites in $\mathrm{MBC}$ and $\mathrm{BC}$ that are not completely desorbed, in addition, there will be a certain loss of MBC and $\mathrm{BC}$ during the separation process. It is worth mentioning that the unit adsorption capacity of MBC decreased from $97.8 \mathrm{mg} / \mathrm{g}$ to $29.1 \mathrm{mg} / \mathrm{g}$ after 5 times of adsorption and desorption. However, the unit adsorption capacity of NMBC decreased from $159.8 \mathrm{mg} / \mathrm{g}$ to 105.5 $\mathrm{mg} / \mathrm{g}$ after 5 times of adsorption and desorption, and the unit adsorption capacity was still $141.2 \mathrm{mg} / \mathrm{g}$ after three times of adsorption and desorption. It can be seen that $\mathrm{MBC}$ has more advantages over $\mathrm{BC}$ in terms of reusability, MBC has good stability and reusability in 3 cycles, and $\mathrm{MBC}$ can be reused 3 times.

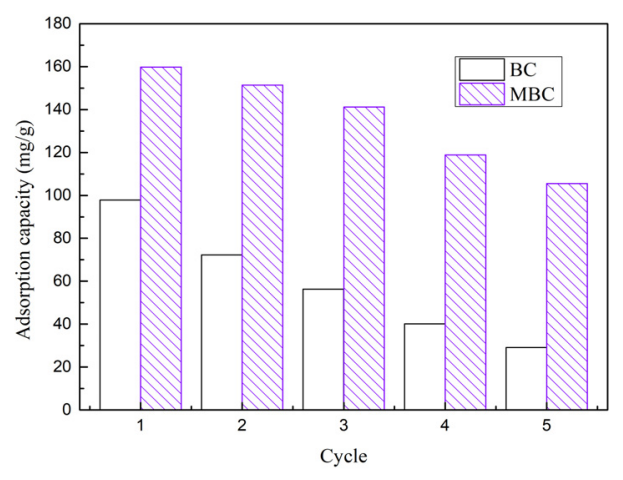

Fig. 4. the recyclability of $\mathrm{BC}$ and $\mathrm{MBC}$

\section{4 conclusion}

(1) The dosage of adsorbent, adsorption time and $\mathrm{pH}$ have a great influence on the unit adsorption capacity of $\mathrm{BC}$ and $\mathrm{MBC}$, and $\mathrm{MBC}$ shows more excellent adsorption performance, this is mainly because the pore structure of MBC is richer, the aromaticity is enhanced, and the hydrophilicity and polarity are also increased, the surface functional groups are more abundant, and the oxygen-containing functional groups are increased.

(2) The recyclability of magnetically modified MBC is better than that of $\mathrm{BC}$, and it has higher application prospects.

\section{Acknowledgements}

This work was supported by the Science and Technology Project of Zhejiang Water Resources Department (NO. RC1830) and "the Fundamental Research Funds for the Colleges” (NO. FRF2019005).

\section{References}

1. T. Chen, L. Luo, S. Deng, et al. Sorption of tetracycline on $\mathrm{H}_{3} \mathrm{PO}_{4}$ modified biochar derived from rice straw and swine manure. Bioresource Technology, 2018, 267: 431-437.

2. Y. Liang, M. Pei, D. Wang, et al. Improvement of soil ecosystem multifunctionality by dissipating manure-induced antibiotics and resistance genes. Environmental Science \& Technology, 2017, 51: 4988-4998.
3. S. Ye, G. Zeng, H. Wu, et al. Co-occurrence and interactions of pollutants, and their impacts on soil remediation-A review. Critical Reviews in Environmental Science and Technology, 2017, 47: 1528-1553.

4. X. Ren, G. Zeng, L. Tang, et al. Sorption, transport and biodegradation-An insight into bioavailability of persistent organic pollut-ants in soil. Science of the Total Environment, 2018, 610-611: 1154-1163.

5. M. Chen, P. Xu, G. Zeng, et al. Bioremediation of soils contaminated with polycyclic aromatic hydrocarbons, petroleum, pesticides, chlorophenols and heavy metals by composting: Applications, microbes and future research needs. Biotechnology Advances, 2015, 33:745-755.

6. S. Ye, G. Zeng, H. Wu, et al. Biological technologies for the remediation of co-contaminated soil. Critical Reviews in Biotechnology, 2017, 37 : 1062-1076.

7. X. Q. Cheng, Z. X. Wang, Y. Zhang, et al. Bioinspired loose nanofiltration membranes with optimized separation performance for antibiotics removals. Journal of Membrane Science, 2018, 554:385-394.

8. S. P. Ghuge, A. K. Saroha, Catalytic ozonation of dye industry effluent using mesoporous bimetallic Ru-cu/SBA-15 catalyst. Process. Saf. Environ. Prot, 2018, 118: 125-132.

9. G. Ramírez, F. J. Recio, P. Herrasti, C. Ponce-deLeón, I. Sirés, Effect of RVC porosity on the performance of $\mathrm{PbO}_{2}$ composite coatings with titanate nanotubes for the electrochemical oxidation of azo dyes, Electrochim. Acta, 2016, 204: 9-17.

10. S. Wong, H.H. Tumari, N. Ngadi, N.B. Mohamed, O. Hassan, R.Mat, N.A. Saidina Amin,Adsorption of anionic dyes on spent tea leaves modified with Polyethyleneimine (PEISTL), J. Clean. Prod, 2019, 206: 394-406.

11. C. R. Holkar, A. J. Jadhav, D. V. Pinjari, N. M. Mahamuni, A. B. Pandit. A critical review on textile wastewater treatments: possible approaches. J. Environ.

12. Manage. 2016, 182: 351-366.

13. T. R. Sahoo, M. Armandi, R. Arletti, M. Piumetti, S. Bensaid, M. Manzoli, S. R. Panda, B. Bonelli, Pure and $\mathrm{Fe}$-doped $\mathrm{CeO}_{2}$ nanoparticles obtained by microwave-assisted combustion synthesis: Physicochemical properties ruling their catalytic activities towards, CO oxidation and soot combustion. Appl. Catal. B: Environ, 2017, 211: 31-45.

14. P. P. Rath, S. S. Behera, B. Priyadarshinia, S. R. Panda, D. Mandal, T. Sahoo, S. Mishra, P. K. Parhi, Influence of $\mathrm{Mg}$ doping on $\mathrm{ZnO} \mathrm{NPs}$ for enhanced adsorption activity of Congo Red dye. Appl. Surface Sci, 2019, 491: 256-266.

15. O. A. Oyewo, M. S. Onyango, C. Wolkersdorfer. Adsorptive performance of surface-modified 
montmorillonite in vanadium removal from mine water. Mine Water Environ, 2017, 36: 628 - 637. 